\title{
THE ANALYSIS OF INITIAL PARAMETERS OF STEAM IN THE COMBINED-CYCLE PLANT WITH HIGH TEMPERATURE GAS TURBINE
}

\author{
Artem Uvarov ${ }^{1}$, Aleksandra Antonova $^{1 a}{ }^{1}$, Aleksandr Vorobjev $^{1}$ \\ ${ }^{1}$ National Research Tomsk Polytechnic University, 634050 Tomsk, Russia ${ }^{a}$
}

\begin{abstract}
Presents the results of studying the influence of initial steam parameters on the thermal efficiency of double-circuit combined-cycle plant based on a powerful hightemperature gas turbines of the last generation. The advantages of double-circuit combinedcycle plant without reheat in comparison with more complex schemes. Found optimal thermal efficiency values of initial parameters of steam.
\end{abstract}

\section{Introduction}

The combined-cycle plants (CCGT) based on the modern gas turbine units (GTU) are the most advanced power plants and the most important part of this plant is the modern gas turbine unit and there are many studies to increase their heat efficiency and the steam turbines effect on the plant efficiency too [1,2]. There is a wide variety of combined-cycle plant schemes but usually the designers prefer three-loop circuit with steam re-heating. It's useful to study the effect of the steam initial parameters on the thermal efficiency of dual-combined-cycle plant with a simpler scheme with simple cost and simple control system but with lower thermal efficiency from the three-loop circuit with steam re-heating $[3,4]$.

The purpose of the study is to find the optimal values of the initial parameters of steam by using different calculations and to choose the best parameters that give the highest thermal efficiency. The choosing priorities for the thermal scheme are simplicity and high reliability.

\section{Research methods}

This paper studies the combined-cycle plant - without steam re-heating, recovery type, on the basis of high-temperature gas turbines Mitsubishi M701J with initial temperature $1600{ }^{\circ} \mathrm{C}$ with nominal efficiency $41 \%$ [5]. Thermal circuit for combined-cycle plant is shown in Fig. 1.

Optimized parameters have initial values for pressure $\mathrm{P}_{0}^{H P}$ and temperature $\mathrm{t}_{0}^{H P}$. The essential condition effects in the choosing of optimum parameters of steam is that the moisture vapor value at the end of expansion must be $y_{\kappa} \leq 11 \%$. This value is lower than its value in the traditional steam turbine plant due to the fact that the increase of the final moisture content in the off-design conditions is because the temperature at the vapor turbine inlet depends on the low gas temperature in the outlet

${ }^{a}$ Corresponding author : anton@tpu.ru 
of gas turbine and because there is no reheating for the steam this determine the rang of the initial pressure values [6].

The mathematical model for the combined plant thermal cycle depends on the balance principle and on the thermodynamical parameters of the working bodies for the working fluids (the gas mixture of air and combustion products - the water and the water vapor) [6,7]. The steam expansion process in the turbine was studied taking in consideration the dependence of the local thermal efficiency on the flow rate ignoring the effect of the heat loss on the humidity and the output speed. The minimum value of the exhaust gas temperature at the outlet of the heat recovery steam generator (HRSG) $80^{\circ} \mathrm{C}$ to prevent low-temperature corrosion to the surfaces.

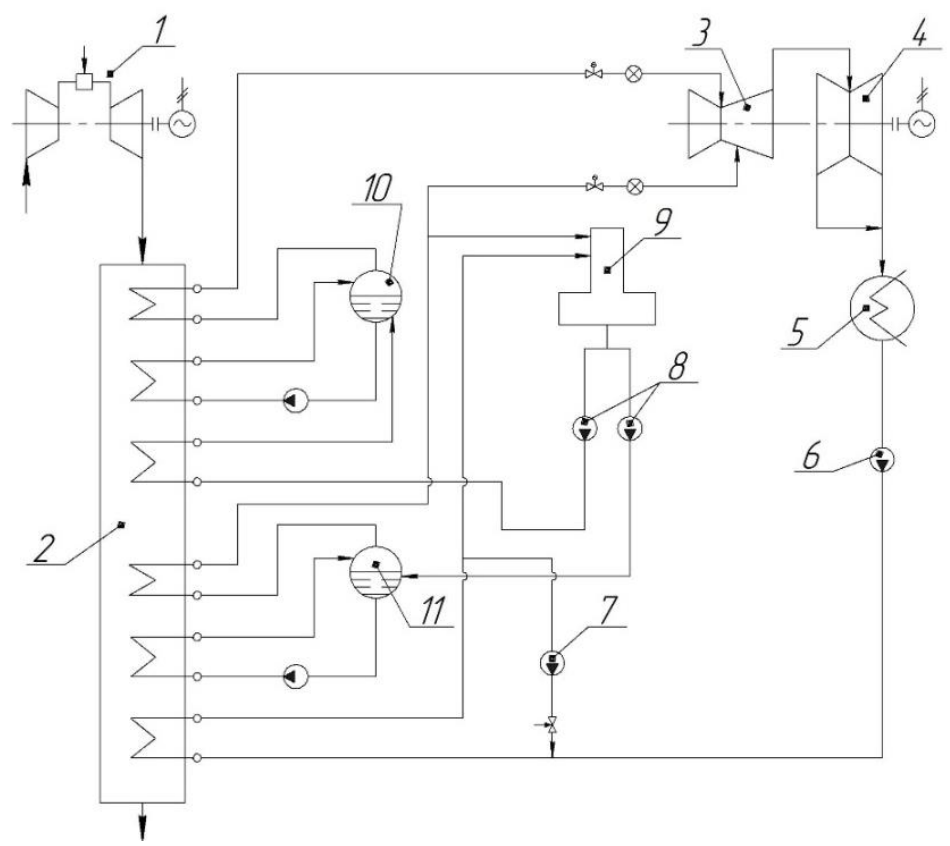

Figure 1. Double-circuit thermal circuit for combined-cycle plant: 1 - gas turbine; 2 - heat recovery steam generator; 3 - HPC; 4 - LPC; 5 - condenser; 6 - condensate pump; 7 - recirculation pump; 8 - HP and LP feedwater pump; 9 - deaerator; 10 - HP drum; 11 - LP drum

The study terms and assumptions:

- the study was made under nominal conditions, which are accepted in accordance with ISO 2314 for gas turbines;

- the steam turbine has two cylinders HPC and LPC, we considered that the low pressure water vapor diagram unaffected with the HPC in the mixing chamber;

- the pressure in the low-pressure (LP) is taken equal to 0,6 MPa to achieve a high thermal efficiency for the CCGT [6];

- the condenser pressure takes the value $5 \mathrm{kPa}$ because this value reduces the low-level parts of the steam turbine and the consumption of cooling water.

Table 1. Initial values of the gas turbine according to the manufacture [8]

\begin{tabular}{|l|c|}
\hline \multicolumn{1}{|c|}{ Parameter, dimension } & Value \\
\hline Electric capacity, MW & 470 \\
Exhaust gas flow, kg/sec & 861 \\
Exhaust gas temperature, ${ }^{\circ} \mathrm{C}$ & 638 \\
Electrical GTU efficiency, \% & 41 \\
\hline
\end{tabular}




\section{Research result}

The results of the variant calculations when change to the initial vapor pressure are presented in Fig. 2. The vertical dashed line in Fig. 2 shows the boundary according to the criterion of maximum permissible values $y_{k}$, the initial pressure of $9.5 \mathrm{MPa}$ is unacceptable.

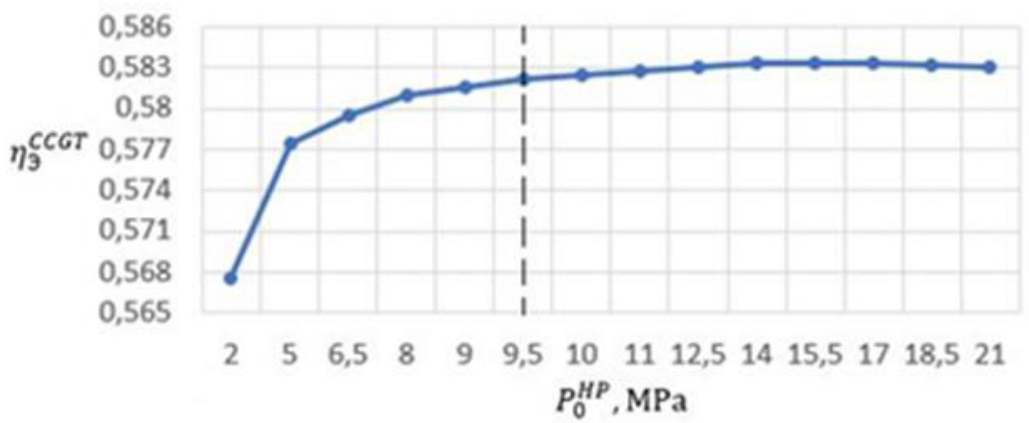

Figure 2. Schedule changes $\eta_{\ni}^{C C G T}$ from the initial pressure $P_{0}^{H P}$

A graph of the efficiency of the CCGT from the initial vapor pressure has character, close to parabolic, with a gently sloping area of the optimum at the boundary of the admissible pressure values, in the range of 14 to $18 \mathrm{MPa}$. A significant increase of the absolute electrical efficiency of CCGT occurs when pressure increases from 2 to $8 \mathrm{MPa}$. With a further increase in the initial pressure up to $17 \mathrm{MPa}$ increase the efficiency of the combined minor, despite the increase in the efficiency of HRSG. This is due to the nature of the change of temperature of turbine, and also with increased final moisture.

In determining the influence of initial steam temperature on the efficiency of the CCGT calculations were performed on the initial pressure $P_{0}^{H P}=9.5 \mathrm{MPa}$, corresponding permissible moisture. The variation of values of initial steam temperature were carried out by changing the temperature difference on the hot side of the superheater of the high pressure circuit in the range from 100 to $20^{\circ} \mathrm{C}$.

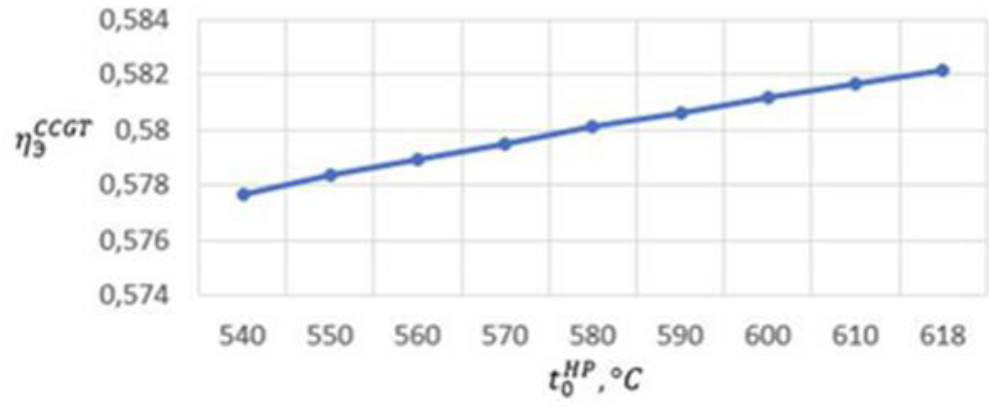

Figure 3. Schedule changes $\eta_{\ni}^{C C G T}$ from the initial temperature $t_{0}^{H P}$

The dependence of the efficiency on the CCGT the initial temperature is linear in nature, with increasing initial temperature there is a noticeable increase in the efficiency of the CCGT, which can be seen from Fig. 3. This fact is explained by the increase in the average temperature of heat supply in the cycle, reduce the final moisture content and a significant increase in efficiency of steam-turbine cycle.

In all embodiments, the flue gas temperature is in the range from 85 to $93{ }^{\circ} \mathrm{C}$, which prevents lowtemperature corrosion of the tail surfaces in HRSG. 


\section{Conclusion}

According to the research results we can draw the following conclusions.

1. Under conditions of permissible steam moisture at the end of the expansion process, the efficiency of the considered combined cycle power plant at the initial vapor pressure of $9.5 \mathrm{MPa}$ reaches a value of $58.2 \%$. It is $5-6 \%$ (abs.) higher than for a similar dual-combined-cycle plant without reheating on the basis gas turbines of previous generations. Achieved in the today's world, the maximum efficiency of a three-loop CCGT supercritical steam parameters of $60-61 \%$, slightly higher than the values obtained and this difference occurs because of the increase in the initial steam parameters (until the supercritical values) with steam reheating and more complicated schemes and it can be expected that this difference in thermal efficiency can offset in the installation cost.

2. The Increase in the initial steam temperature at a constant pressure increases the thermal efficiency of combined cycle power plant and reduce the moisture content in the turbine. Getting to the maximum possible steam temperature needs a very big heating surface area because of the low temperature difference and this increases the equipment and pipelines cost, which requires feasibility study.

The work has been done in framework of federal focused program implementation “Competitiveness Enhancement Program” of National Research Tomsk Polytechnic University.

\section{References}

1. G. Olkhovsky, V. Trushechkin, Therm. Power Plants, 1, 2 (2013)

2. A. Kultyshev, M. Stepanov, E. Polyaeva, Therm. Eng, 61, 861 (2014)

3. T. Ibrahim, M. Rahman, Adv. Mech. Eng., 2014, Article ID 781503 (2014)

4. A. Bassily, Appl. Therm. Eng., 40 (2012)

5. Gas Turbine. World 2014 Specs 30th edition, 44, 1 (2014)

6. A. Trukhniy, Parogazovyye ustanovki elektrostantsiy (MEI, 2013)

7. N. Hasan, J. Rai, B. Arora, SpringerPlus, 3, 1 (2014)

8. M701J series [Electronic resource] // Mitsubishi Hitachi Power Systems [Official website]. URL: https://www.mhps.com (accessed: 20.05.2015) 